\title{
La ontología naturalista de Spinoza como ontología de la pasión
}

\author{
Spinoza's naturalistic ontology \\ as ontology of passion
}

\author{
Inmaculada Hoyos SÁNCHEZ \\ (Universidad de Granada)
}

Recibido: 04/10/2011

Aceptado: 19/04/2012

\section{Resumen}

El objetivo de este trabajo es doble. En primer lugar, se trata de mostrar que la ontología de Spinoza es naturalista porque concibe lo real como Naturaleza y desde esta concepción combate toda forma de mistificación y fundamentalmente aquella que nos presenta lo real como algo sobrenatural y trascendente a la naturaleza misma. En segundo lugar, se trata de poner de manifiesto que en virtud de los rasgos propios del naturalismo spinoziano, a saber, su dinamismo y sus elementos materialistas, la ontología de Spinoza es una ontología de las pasiones. Las pasiones son, en la filosofía de Spinoza, modos de ser, modos finitos, humanos, de ser.

Palabras clave: Spinoza, ontología, naturalismo, pasión.

\begin{abstract}
The aim of this paper is twofold. Firstly, it deals with showing that Spinoza's ontology is naturalistic because it conceives of reality as nature, and, in this way, it combats all form of mystification that presents us the reality as something supernatural and transcendent nature itself. Secondly, it deals with showing, according to characteristic features of Spinoza 's naturalism, that is, its dynamism and its materialistic elements, that Spinoza's ontology is an ontology of the passions. The passions are, according to Spinoza's philosophy, modes of being, finite, human modes of being.
\end{abstract}

Keywords: Spinoza, ontology, naturalism, passion. 


\section{Introducción: naturalismo y pasión}

El título de este estudio es "la ontología naturalista de Spinoza como ontología de la pasión". Es cierto que el término "naturalismo" tiene una larga historia, y, con ella, diversos significados y valencias. Sin embargo, y al igual que ocurre con las pasiones, en las últimas décadas ha dejado de ser un término denostado para ir adquiriendo matices y ser recuperado por todos aquellos que ven en la filosofía de Spinoza una ontología de la inmanencia1. De aquí parte el presente trabajo. Su contribución, en este sentido, reside en aportar argumentos que apoyan la interpretación naturalista de la filosofía spinoziana. En concreto, el propósito de este estudio es triple: en primer lugar, se trata de mostrar que efectivamente la ontología de Spinoza es naturalista; en segundo lugar, se trata de precisar qué tipo de naturalismo es el genuinamente spinoziano; y en tercer lugar, se trata de poner de manifiesto que en virtud de los rasgos propios del naturalismo spinoziano, la ontología de Spinoza es una ontología de las pasiones, es decir, concibe las pasiones como modos de ser. También durante muchos años la reflexión sobre las pasiones se consideró una cuestión sugerente, pero tan sólo secundaria en el pensamiento de Spinoza. Sin embargo, desde los años 60 del siglo pasado, se ha producido una recuperación y revalorización de la filosofía de las pasiones de Spinoza como una cuestión central de su pensamiento, en la que convergen problemas ontológicos, éticos, epistemológicos, etc.. ${ }^{2}$ En este sentido, una de las aportaciones de este trabajo reside en mostrar la dimensión ontológica que tienen las pasiones en la filosofía de Spinoza a partir del naturalismo que es propio de su ontología.

Sin embargo, como decía, el término "naturalismo" es un término polisémico y polémico, y por ello, es necesario, aclarar, en primer lugar, qué significa ser naturalista desde un punto de vista ontológico. En este sentido, propongo partir de una definición mínima de "naturalismo" según la cual éste es una actitud filosófica que mantiene que la Naturaleza, y las cosas en ella, son las únicas realidades existentes, oponiéndose, de este modo, a todo sobrenaturalismo, es decir, a la idea de que más allá de este mundo natural, hay otro mundo trascendente no natural ${ }^{3}$. El naturalis-

\footnotetext{
1 Cf. Deleuze, G. : Spinoza et le problème de l'expression, Paris, Editions de Minuit, 1969; Íd.: Spinoza. Philosophie pratique, Paris, PUF, 1970 ; Negri, A. : L'anomalia selvaggia. Saggio su potere e potenza in Baruch Spinoza. Milán, Feltrinelli, 1981; Yovel, Y.: Spinoza: el marrano de la razón, Madrid, Anaya \& Mario Muchnik, 1995. [ Trad. M. Cohen].

2 Uno de los puntos de partida fundamentales de este despertar de la investigación en torno a los afectos en la filosofía de Spinoza tiene lugar con el trabajo de Matheron, A.: Individu et communauté chez Spinoza, Paris, Les Editions Minuit, 1969. Para una magnífica reconstrucción de la historia y el estado de la investigación acerca de los afectos en Spinoza, véase la introducción de Fernández, E. \& De la Cámara, M. L. (eds.) : El gobierno de los afectos en Baruj Spinoza, Madrid, Trotta, 2007.

3 Cf. Ferrater Mora, J.: Diccionario de filosofía, Barcelona, Ariel, 1994, p. 2507. (1 a ed. revisada y actualizada en Ariel Referencia).
} 
mo es, pues, una ontología de la inmanencia, y, tal y como señala Deleuze, es una ontología de la inmanencia que lucha contra las mistificaciones que, ya sean del signo que sean, se apoyan en la desazón del alma y la tristeza para asentar su poder4. De este modo, la primera tarea que hay que realizar consiste en mostrar, a partir del análisis del libro I de la Ética, que la ontología de Spinoza es naturalista justamente en este sentido y, que, por tanto, satisface los tres requisitos antes mencionados. Lo primero es, pues, poner de manifiesto que Spinoza concibe lo real como Naturaleza.

\section{Naturalismo y panteísmo. Todo es Naturaleza}

Deus sive Natura afirma Spinoza en el Tratado Breve. Pero también la Naturaleza está presente en la ecuación Deus sive Substantia de la Ética. En este sentido, es muy conocida la tesis según la cual el Tratado Breve se basa en la ecuación Dios=Naturaleza, mientras que la Ética lo hace en la ecuación Dios=Sustancia5 ${ }^{5}$ El motivo fundamental del Tratado Breve es que todas las sustancias pertenecen a una sola e igual Naturaleza, mientras que el de la Ética es que todas las naturalezas pertenecen a una sola y misma sustancia." 6 Y así, el naturalismo inicial del Tratado Breve se transforma en el panteísmo o sustancialismo de la Ética ${ }^{7}$. Dicho de otro modo, pasamos de la identificación directa entre Dios y la naturaleza al protagonismo de Dios como Sustancia, que sólo posteriormente se identifica con la Naturaleza. 8

Ahora bien, la tesis que aquí se mantiene es que en la Ética el naturalismo no se pierde, sino que se lleva hasta sus últimas consecuencias (o penúltimas, pues en el libro V los fantasmas del "sobrenaturalismo" podrían volver a hacer aparición)9. La evolución de la filosofía de Spinoza desde el Tratado Breve hasta la Ética (con

\footnotetext{
${ }^{4}$ Cf. Deleuze, G.: Lógica del sentido, Barcelona, Seix Barral, 1971, pp. 354-355. [Trad. A. Abad]

5 Cf. Gueroult, M. : Spinoza. Dieu (Ethique I), vol. I, Paris, Aubier, 1968, apéndice nº 6, pp. 471-487, especialmente, pp. 473-487.

6 Deleuze, G.: Spinoza: filosofía práctica, Barcelona, Tusquets, 2001, (1 ${ }^{\mathrm{a}}$ ed. en Tusquets Fábula), p.135. [Trad. A. Escohotado].

7 Uno de los autores que ha mantenido la interpretación panteísta de la ontología spinoziana es A. Matheron: 'Dieu n'est pas extérieur à l'Individu infini ; il n'est pas non plus extérieur aux individus finis, même s'il déborde infiniment chacun d'entre eux pris à part : il est ce qui, en eux, les fait être et les fait comprendre. Deus quatenus : le panthéisme fonde l'individualisme métaphysique" (Matheron, A.: op. cit.,p. 21).

8 Cf. Espinosa Rubio, L.: Spinoza: Naturaleza y Ecosistema, Salamanca, Publicaciones Universidad Pontificia de Salamanca, 1995, p. 19.

9 En este sentido se desarrolla el trabajo de G. Deleuze que parte de los escritos de Gueroult. Deleuze reconoce que hay diferencias entre el naturalismo inicial y el panteísmo final, pero subraya que el naturalismo no se pierde. (cf. Deleuze, G.: Spinoza: filosofía práctica, ed. cit., pp. 135-136).
} 
la excepción de los Principios de la filosofía de Descartes y Pensamientos metafisicos, que merecen una consideración aparte) habría que plantearla, pues, en términos de un creciente naturalismo más que de un panteísmo10; naturalismo que, además, ve su máxima expresión, en lo que atañe al campo práctico, en la última obra de Spinoza: su Tratado Político. Aunque sea más una cuestión de énfasis que de diferencias radicales en la interpretación, y a riesgo de entrar en la discusión prácticamente interminable entre ambos, es preferible el término "naturalismo" al de "panteísmo" por las razones que se aducirán a continuación.

En primer lugar, en la ecuación Dios=Sustancia, que es la aportación de la Ética, sigue estando presente la ecuación Dios=Naturaleza, de modo que el naturalismo del Tratado Breve se ve realizado más plenamente en la obra de madurez del pensamiento de Spinoza. La proposición 14 establece que no puede darse ni concebirse sustancia alguna excepto Dios, y, su primer corolario, señala que de ello se sigue muy claramente que "Deum esse unicum, hoc est in rerum natura non, nisi unam substantiam, dari, eamque absolute infinitam esse."11 Corrige así la ontología cartesiana, convirtiendo a la sustancia extensa y la sustancia pensante en dos atributos de esta única Sustancia12. Pero lo que me interesa resaltar aquí es que entre la Naturaleza y la Sustancia única hay una relación de continuidad, e incluso, de cierta identidad. En la Naturaleza no hay sino una única Sustancia. La Naturaleza no es sino una única Sustancia. Esa Sustancia, tal y como afirma la proposición 14, es Dios. Luego, entre Naturaleza, Sustancia y Dios hay una relación de identidad. Y así, la ecuación Natura sive Deus, sigue estando presente, de manera implícita en la ontología que nos presenta la Ética, ahora sí, mediada por otra ecuación que es la de Natura sive Substantia. 13 De este modo, "Naturaleza" sigue siendo uno de los términos, junto con el de "Sustancia" y "Dios", que Spinoza emplea para designar lo real.

\footnotetext{
10 En el apéndice n ${ }^{\circ} 6$ del volumen I de su Spinoza, Gueroult distingue en la evolución del Tratado Breve hasta la Ética, tres estadios, representados por los Diálogos entre el Entendimiento, el Amor y la Razón, El Tratado Breve propiamente dicho y el apéndice geométrico de éste último, tendentes a un mayor panteísmo. (cf. Gueroult, M.: op. cit., p. 487.)

11 Spinoza, B.: Ética, I, 14, corol. I (Geb. II, 56) (62). Las referencias a la obra de Spinoza llevan entre paréntesis la indicación Carl Gebhardt (Geb.), tomo y página correspondiente a la edición Spinoza. Opera, Heidelberg, Carl Winters Universitätsverlag, 1972. A continuación, también entre paréntesis, aparece la página correspondiente a la edición castellana de las obras de Spinoza. En el caso de la Ética (E), citamos según la edición preparada por Vidal Peña, Madrid, Alianza Editorial, 1987 (5 reimp. 2006).

12 Cf. E, I, 14, corol. II (Geb. II, 56) (62).

13 Esta tesis se corrobora en la demostración de la proposición 30, donde aparece la ecuación de los tres términos de manera expresa. "In natura non nisi una substantia datur, nempe Deus; nec ullæ aliæ affectiones, quam quæ in Deo sunt, \& quæ sine Deo nec esse, nec concipi possunt" E, I, 30, dem. (Geb. II, 71) (84).
} 
No obstante, puede mantenerse una segunda tesis más fuerte, arguyendo que el término "Naturaleza" goza de cierta primacía, con respecto a los otros dos términos que Spinoza emplea para referirse a la realidad. El concepto de Naturaleza es el concepto más amplio que Spinoza tiene para denominar lo real. De hecho, es este término el que emplea para distinguir las diferentes perspectivas de lo real, que son de lo real mismo y no sólo del sujeto que lo contempla. Y así nos habla de la Natura naturans y de la Natura naturata, y no de un Dios divinizante y un Dios divinizado, o de la Sustancia sustantivante y de la Sustancia sustantivada. Es en el escolio de la proposición 39 donde aparece de forma más clara que el concepto más comprehensivo de lo real es la Naturaleza, que lo real es Naturaleza, naturante y naturada, pero siempre Naturaleza. En este escolio Spinoza elige el concepto de Natura para englobar los dos puntos de vista de lo real, el punto de vista de la Natura naturans, que se refiere a Dios o la Sustancia en sí misma y sus atributos, y la Natura naturata, que se refiere a los modos de la Sustancia. Aunque ambas distinciones no atañen a una distinción real, esto es, no implican dualismo ontológico. Se trata siempre de una y única Naturaleza, que se expresa de formas diversas.

Es cierto, como se ha dicho antes, que la Naturaleza es Sustancia. Y también sabemos que la Sustancia se expresa en los modos, y que los modos son afecciones de la Sustancia, por las cuales ésta expresa su naturaleza de cierta y determinada manera ${ }^{14}$, es decir, sabemos que también la Sustancia es una y única y que tiene una relación tal con los modos que no hay separación ontológica entre ellos. Y entonces, la "Sustancia" o "Dios" ¿podrían ser, al igual que la "Naturaleza", los términos más comprehensivos para denominar lo real? No exactamente. Por supuesto, que lo real es una única Sustancia, que en la naturaleza sólo hay una Sustancia, y que no hay algo así como una Naturaleza por encima o más allá, como si ésta fuese una sustancia distinta de aquella. Por supuesto que los modos no tendrían realidad separados de la Sustancia, y que ésta sólo sería una abstracción, si se la separa de estos modos en los que se expresa. Pero la Sustancia no es propiamente un modo, ni el modo es Sustancia.

En la segunda mitad del libro I de la Ética, cuando Spinoza caracterice a la Natura naturata, quedará de manifiesto que los modos no comparten esencia con Dios. Tienen características diferentes. Todo no es Dios. Y, sin embargo, sí se puede decir que todo es Naturaleza; naturante y naturada, pero todo Naturaleza. Y ello nos lleva a concluir de nuevo que lo real es Sustancia o Dios y modo, pero, sobre todo, lo real es Naturaleza.

Hay que analizar, pues, las características que presenta la Natura spinoziana con el objetivo de mostrar no sólo que Spinoza es naturalista porque concibe lo real como Naturaleza, sino también porque en virtud de las características que atribuye

14 Cf. E, I, 25, corol. (Geb. II, 68) (80). 
a la Naturaleza, satisface las otras dos condiciones que caracterizan al naturalismo, a saber, la oposición a todo sobrenaturalismo y la crítica o empresa de desengaño con respecto a toda ontología de la trascendencia que se vale de la tristeza para asentar su poder.

\subsection{Natura naturans: infinitud, impasibilidad y amoralidad}

En primer lugar, y desde el punto de vista de la Natura naturans, lo real aparece como Sustancia o Dios, y por tanto, como causa sui, de existencia necesaria, infinito, indivisible, eterno, inmutable. Se puede decir que con ello aparecen las características que tradicionalmente se habían atribuido a lo real, a lo que es ser, y no a lo meramente aparente. Ahora bien, junto con estas características más "tradicionales", empiezan a perfilarse otras más originales, que dan lugar a una nueva visión de la ontología. La primera de estas características es aquella que se basa en la potencia como esencia de todas las cosas. "Dei potentia est ipsa ipsius essentia."15 Pero ¿qué entiende Spinoza por potencia?

En primer lugar, la potencia no se concibe en un sentido aristotélico, como lo que se opone al acto, como potencialidad que debe actualizarse. La potencia spinoziana se define por referencia a la existencia y a la fuerza. "Poder no existir es impotencia, y, por contra, poder existir es potencia (como es notorio por si)." $16 \mathrm{Y}$ "siendo potencia el poder existir se sigue que cuanta más realidad compete a la naturaleza de una cosa, tantas más fuerzas tiene para existir por sí; y, por tanto, un Ser absolutamente infinito, o sea Dios, tiene por sí una potencia absolutamente infinita de existir, y por eso existe absolutamente." 17 La potencia es, pues, fuerza, y fuerza para existir (que no para dominar). Tiene, pues, una dimensión ontológica insoslayable. La potencia define la esencia de Dios y también la del resto de cosas que son. Lo que ocurre es que cuando consideramos a la realidad desde el punto de vista de Dios en sí mismo, de la Sustancia y sus infinitos atributos, de la Natura naturans, lo real es potencia infinita. Y ¿por qué? Porque, como nos ha dicho Spinoza, cuanta más realidad compete a la naturaleza de una cosa, tanta más fuerza tiene para existir por sí; de modo que como Dios es un Ser absolutamente infinito ${ }^{18}$, tiene por sí una potencia absolutamente infinita de existir y por eso existe absolutamente. Entre potencia, fuerza y realidad hay, pues, un vínculo muy estrecho. Hay una relación directamente proporcional, de modo que cuanta más realidad tenga algo, tanta más fuerza o más potencia tendrá también.

\footnotetext{
15 E, I, 34 (Geb. II, 76) ( 94).

16 E, I, 11, dem. (Geb. II, 53) (58). Nótese que esta consideración de la potencia no necesita demostración. Es evidente de por sí, tal y como señala Spinoza.

17 E, I, 11, schol. (Geb. II, 54 ) (59).

18 Cf. E, I, def.VI (Geb. II, 45) ( 47) .
} 
Además, esta realidad con la que va asociada de manera idéntica la potencia, también recibe otra denominación: la perfección. Así parece entenderse a lo largo del libro I donde en diversas demostraciones la perfección se entiende en el sentido de realidad, como luego explícitamente establece en la definición VI del libro II de la Ética ${ }^{19}$. En el caso de la Natura naturans, de la Sustancia o Dios, la infinitud marca de nuevo la diferencia con respecto a las cosas singulares. Puesto que Dios es infinito, su realidad también lo es, y por tanto, su perfección y su existencia son absolutas, necesarias como las de ninguna otra cosa. La perfección o realidad de Dios no se debe a causa externa alguna, sino que procede solamente de ella misma. En cambio, la perfección o realidad de las cosas singulares, esto es, de todo aquello que no es Sustancia, de la Natura naturata, se debe a la perfección y realidad de las causas que las producen. De ahí concluirá Spinoza que la existencia de Dios se sigue de su sola naturaleza, es decir, de su esencia; mientras que la existencia de los modos, se debe a Dios o la Sustancia de la que son modos ${ }^{20}$. Y así, la Natura naturans, Dios o la Sustancia, es causa de sí y libre; mientras que la Natura naturata, no lo es.

"Solum Deum esse causam liberam."21 Ahora bien, ¿cómo hay que entender esta libertad? En la definición VII del libro I nos dice Spinoza que se llama libre a aquella cosa que existe en virtud de la sola necesidad de su naturaleza y es determinada por sí sola a obrar; y necesaria, o mejor compelida, a la que es determinada por otra cosa a existir y operar, de cierta y determinada manera. La visión de lo real que tiene Spinoza es determinista. Todo está determinado. En la naturaleza, o más precisamente en la Natura naturans, no hay nada contingente. ${ }^{22}$ Lo contingente o posible, tal y como lo define Spinoza en el libro I, es tan sólo una deficiencia de nuestro conocimiento. Sólo porque desconocemos la esencia de las cosas y sus causas, creemos que son contingentes. ${ }^{23} \mathrm{Y}$ entonces, ¿qué espacio queda para la liber-

\footnotetext{
19 Habría que precisar aquí que en la Ética aparecen dos nociones de perfección. Por una parte, en los libros I y II se toma la perfección como sinónimo de realidad (noción metafísica de perfección). Pero en el prefacio del libro IV se dice que la perfección y la imperfección son, como el Bien y el Mal, el Orden y el Desorden, etc., modos de pensar (noción ética de perfección). Para la cuestión de la compatibilidad o no de estas dos nociones de perfección, véase el excelente trabajo de García Leal, J. : "El naturalismo ético en Spinoza", Ágora: papeles de filosofía, 4, 1984, pp. 67-86, especialmente, pp. 70-76.

20 Cf. E, I, 11, schol. (Geb.II, 54) (59).

${ }^{21} \mathrm{E}, \mathrm{I}, 17$, corol. II (Geb. II, 61) (68).

22 "En la naturaleza no hay nada contingente, sino que en virtud de la necesidad de la naturaleza divina, todo está determinado a existir y obrar de cierta y determinada manera" E, I, 29 (Geb. II 70) (83). No obstante, esta afirmación aparece en el libro I. Sin embargo, a partir del libro II Spinoza elabora otro concepto de contingencia, que ya aparece claramente en el libro IV, y que permite precisar la afirmación anterior diciendo que en la Natura naturans no hay nada contingente, pero sí en la Natura naturata. A esta cuestión volveré en la sección 2.2. dedicada a analizar las características de la Naturaleza naturante.

23 Cf. E, I, 33, schol. I (Geb. II, 74) (90).
} 
tad? La libertad sólo puede concebirse como autodeterminación. "Dios obra en virtud de las solas leyes de su naturaleza, y no forzado por nadie."24 Por eso es causa libre, esto es, porque es y actúa en virtud de la sola necesidad de su naturaleza. Su determinación procede de sí mismo y no de causas externas. Pero esto no quiere decir que Dios puede producir las cosas que ha producido de otra manera y en algún otro orden que como lo han sido. ${ }^{25}$ Dios no tiene una voluntad libre. "Deum non operari ex libertate voluntatis." 26 Atribuir a Dios una libertad entendida como voluntad absoluta, no sólo es algo fútil sino también un obstáculo para la ciencia. 27 Es más, no es que Dios no tenga una voluntad libre, es que ni siquiera puede atribuírsele voluntad, ni entendimiento. Tanto una como otro son modos de pensar. Y como tales modos, no deben atribuirse a la Natura naturans, sino a la Natura naturata. 28 Dios no es sujeto. La Sustancia no es sujeto. La Naturaleza o lo real contemplado desde esta perspectiva no es sujeto.

Sólo desde el prejuicio del antropomorfismo y la superstición se puede concebir a un Dios dotado de una voluntad que tiende a un fin libremente elegido. Todos los prejuicios que provocan una mala comprensión de la naturaleza de Dios dependen de uno solo, a saber, "de que los hombres supongan, comúnmente, que todas las cosas de la naturaleza actúan, al igual que ellos mismos, por razón de un fin, e incluso tienen por cierto que Dios mismo dirige todas las cosas hacia un cierto fin, pues dicen que Dios ha hecho todas las cosas con vistas al hombre, y ha creado al hombre para que le rinda culto." 29 La concepción teleológica de la naturaleza y de Dios mismo, son resultado de una proyección antropomórfica. Son el resultado de una mala comprensión, de un mal punto de vista, de una mala perspectiva de la Naturaleza y, por tanto, de Dios, y también del hombre mismo.

Además, la consecuencia principal que se deriva de mantener una concepción finalista, antropocéntrica y antropomórfica de la realidad es la formación de los conceptos de Bien/Mal, Orden/Confusión, Bello/Feo, para explicar la naturaleza de las cosas. La idea es que los hombres juzgan el valor de las cosas de acuerdo con su utilidad y a partir de ahí conciben el Bien, como todo aquello que conduce a la salud y al culto de Dios, y el Mal, como lo contrario. Ahora bien, como piensan que todas las cosas están hechas con vistas a la satisfacción del hombre, aplican erróneamente esos conceptos a la naturaleza en sí misma y piensan así que el Bien y el Mal, el Orden y el Desorden, son cualidades o propiedades intrínsecas de ésta. Sin embargo, tales nociones "tampoco son otras cosas que modos de imaginar, por los

\footnotetext{
24 E, I, 17(Geb. II, 61) (68).

25 Cf. E, I, 33 (Geb. II, 73) (89).

26 E, I, 32, corol, I (Geb. II, 73) (88).

27 Cf. E, I, 33, schol. II (Geb. II, 74-75) (91).

28 Cf. E, I, 31 (Geb. II, 71) (85).

29 E, I, Appendix (Geb. II, 78) (96).
} 
que la imaginación es afectada de diversas maneras,"30 es decir, el bien y el mal tienen por objeto la relación que nosotros mantenemos con la naturaleza y no la naturaleza en sí misma. Desde este punto de vista, es decir, desde el punto de vista de la Natura naturans, todo es como tiene que ser. No hay imperfección, ni vicio alguno que atribuir a la naturaleza pues "la perfección de las cosas debe estimarse por su sola naturaleza y potencia, y no son más o menos perfectas porque deleiten u ofendan los sentidos de los hombres, ni porque convengan o repugnen a la naturaleza humana." 31 Desde esta perspectiva, no hay, pues, bien ni mal alguno. La Natura naturans está más allá de las valoraciones morales, pues en ella todo ocurre con necesidad e independientemente de los dictados de nuestra utilidad. Y así, que la naturaleza no obedezca a nuestra conveniencia no significa que nos sea hostil. Significa tan sólo que es inocente, es decir, que no hay culpa en ella, que no puede ser juzgada, ni castigada, porque la necesidad que la recorre excluye toda posible virtud y todo posible vicio. 32

Esta crítica de Spinoza a la "metafísica de la llamada de los valores," 33 a saber, aquella que mantiene que hay unos valores superiores (orden, belleza, armonía) que son objetivos y que actúan como motores inmóviles de nuestro amor, llamando a nuestros deseos, tendrá unas consecuencias teóricas y prácticas que son de suma importancia. En concreto, desmota toda la alienación ideológica que se teje en torno a esta metafísica y que reside en la elaboración de una versión inversa del mundo en la que se reflejan las grandes líneas del cosmos tradicional que aquí son criticadas por Spinoza (finalidad universal, jerarquía de los seres según el Bien) y que, la mayoría de las veces, dan lugar a la creencia en otro mundo, trascendente al nuestro, que sería su modelo. ${ }^{34}$ De momento lo que conviene señalar es que el Dios de Spinoza, convertido en Naturaleza, es, según el razonamiento antes desarrollado, amoral. Y esta característica suya es muy relevante porque va asociada con otra: la impasibilidad de Dios.

"Sic etiam, qui naturam divinam cum humana confundunt, facile Deo affectus humanos tribuunt, praesertim quamdiu etiam ignorant, quomodo affectus in mente

\footnotetext{
30 Loc. cit. (Geb. II, 82) (103).

31 Loc. cit. (Geb. II, 83) (104).

32 Cf. Ávila, R.: "Finalidad, deseo y virtud: Spinoza y Nietzsche", Anales del Seminario de Metafísica, 20, 1985, pp. 27-28. Es uno de los puntos en común entre Nietzsche y Spinoza.

33 La expresión "llamada de los valores" la toma A. Matheron de Goldschmidt, M.: Les Dialogues de Platon. Structure et méthode dialectique, Paris, P.U.F., 1947; cf. Matheron, A. : op. cit., nota 65, p. 105. Matheron piensa en la filosofía platónica en particular y cree que Spinoza podría estar pensando en los valores superiores del Filebo de Platón. (Loc. cit., p. 111).

34 En este sentido, Matheron se refiere a la alienación ideológica, y a la alienación mundana, por la que sacralizamos ciertos bienes a cuya persecución consagramos nuestra existencia. Tanto la alienación mundana como la ideológica dirigen, en cierto modo, nuestra vida pasional. (cf. Matheron, A.: op. cit., pp. 90-112.)
} 
producuntur." 35 Ya desde el comienzo del libro I aparece, pues, la crítica a la proyección antropomórfica dirigida, en este caso, al retrato de un Dios afectivo. De igual modo, al final de este libro I, se muestra indirectamente que Dios no padece nunca. En este sentido, Spinoza señala que "Intellectus actu, sive is finitus sit, sive infinitus, ut et voluntas, cupiditas, amor etc. ad Naturam naturatam; non vero ad naturantem referri debent." 36 Esta tesis, además, se mantiene hasta el final de la Ética. En el libro V Spinoza vuelve a repetir que "Deus expers est passionum, nec ullo Lætitiæ, aut Tristitiæ affectu afficitur." 37 Y ello porque, según explica el filósofo, Dios no puede pasar ni a una mayor ni a una menor perfección. Dios es inmutable. ${ }^{38} \mathrm{Su}$ existencia y su esencia son uno y lo mismo. Ambas son verdades eternas. Y así, si Dios pudiese cambiar por razón de la existencia, también debería hacerlo por razón de esencia, lo cual es absurdo. Sería lo mismo que decir que lo verdadero puede transformarse en falso. Dios no está sujeto, pues, a la transición hacia una mayor o menor perfección en la que consisten las pasiones. ${ }^{39}$ Dios es un ser absolutamente infinito, con una realidad infinita y una perfección infinita, y, por tanto, el ascenso a una mayor perfección, o el descenso a una menor, no son posibles. 40

De este modo, negar que Dios sea pasivo, esto es, que tenga pasiones, es algo incuestionable en el pensamiento de Spinoza. Puede admitir, y de hecho no sólo admite sino que concibe un Dios extenso o material, con tal de que no padezca, con tal de que no se lo antropomorfice y se piense como dependiente de un fin. "Confieso - reconoce el filósofo- que la opinión que somete todas las cosas a una cierta voluntad divina indiferente, y que sostiene que todo depende de su capricho, me parece alejarse menos de la verdad que la de aquellos que sostienen que Dios actúa en todo con la mira puesta en el bien, pues éstos últimos parecen establecer fuera de Dios algo que no depende de Dios, y a lo cual Dios se somete en su obrar como a un modelo, o a lo cual tiende como a un fin determinado. Y ello, sin duda, no significa sino el sometimiento de Dios al destino, que es lo más absurdo que puede afirmarse de Dios." 41 Si Dios actuase en función de fines, necesariamente apetecería algo de lo que carece; algo que fuera de él, actuaría como modelo (el Bien o el Destino) y a lo que Dios estaría sometido. Pero esto es absurdo porque

\footnotetext{
35 E, I, 8, schol. II (Geb. II, 49) (52).

36 E, I, 31 (Geb. II, 71) (85).

37 E, V, 17(Geb. II, 291) ( 402).

38 Cf. E, I, 20, corol. II (Geb. II,, 65)( 75).

${ }^{39}$ Así consta en las definiciones que de la alegría y la tristeza nos ofrece Spinoza en el libro III de la Ética. Cf. E, III, 11, schol. (Geb. II, 149) (207).

40 Sin embargo, en el hombre esto no ocurre, es decir, precisamente porque su esencia no es igual a su existencia, su esencia o realidad podría permanecer invariable y esto no imposibilita que el hombre esté sujeto a variaciones existenciales. Este argumento que Spinoza esgrime aquí para mostrar la impasibilidad divina, no es válido para el caso del hombre.
}

41 E, I, 33, schol. II (Geb. II,76) (93-94). 
Dios no carece de nada. Es sumamente perfecto ${ }^{42}$. No puede querer, no puede apetecer nada.

No obstante, esto no quiere decir que Spinoza no conceda un espacio ontológico para las pasiones, y aún más todavía, para los afectos. Hemos visto antes que el entendimiento, sea infinito o finito, así como la voluntad, el deseo, el amor y otros modos del pensar son precisamente eso, modos, y como tales, deben atribuirse a la Natura naturata y no a la Natura naturans, esto es, no pueden atribuirse a Dios, pero sí a los modos. Y así, los afectos y, con ellos, las pasiones, tendrán también una dimensión ontológica. Pero ésta sólo atañe a esa respectividad de lo real que es la Naturaleza naturada. Sólo cuando lo real se expresa desde este punto de vista aparece coloreado de afectos y de pasiones.

De momento, sin embargo, conviene retener esta tesis de Dios como ser impasible. Dios no puede padecer. En esto Spinoza está de acuerdo con la mayor parte de la tradición filosófica. Y sin embargo, el Dios de Spinoza, como se viene mostrando, no es el Dios de la metafísica tradicional. Otro signo de ello se encuentra en la tesis spinoziana de la Extensión o materia como atributo divino. ${ }^{43}$ Es una de las diferencias más relevantes entre la ontología de Descartes y la de Spinoza. La res extensa cartesiana se convierte en un atributo divino en la filosofía de Spinoza y ello tendrá consecuencias de mucho alcance.

"Todos cuantos han examinado de algún modo la naturaleza divina - advierte Spinoza- niegan que Dios sea corpóreo (...). Sin embargo, al mismo tiempo se esfuerzan por demostrar con otras razones, y manifiestan claramente, que ellos consideran la sustancia corpórea o extensa como separada por completo de la naturaleza divina, y la afirman creada por Dios. Pero ignoran totalmente en virtud de qué potencia divina haya podido ser creada; lo que claramente muestra que no entienden lo que ellos mismos dicen. Yo, al menos, he mostrado con bastante claridad a mi juicio que ninguna sustancia puede ser producida o creada por otra cosa. Además he demostrado que excepto Dios, no puede darse ni concebirse sustancia alguna; y de ello hemos concluido que la sustancia extensa es uno de los infinitos atributos de Dios."44 Aún así Spinoza dedica un largo escolio a refutar los argumentos de tales adversarios. Y a lo largo de esta refutación, y esto es en lo que quiero hacer hinca-

\footnotetext{
42 Cf. E, I, Appendix (Geb. II, 80)( 100).

43 En este sentido, precisa Ch. Jaquet que Spinoza no habla tanto de materia cuanto de extensión porque Spinoza, como Descartes, reduce la primera a la segunda. (cf. Jaquet, Ch. : Les expressions de la puissance d'agir chez Spinoza, Paris, Publications de la Sorbonne, 2005, p. 212). También, en este sentido, es relevante el trabajo de Giancotti sobre el materialismo en la filosofía de Spinoza y que, salvo por la referencia a Descartes, está de acuerdo con la tesis de Jaquet. Giancotti afirma que la extensión como atributo divino tiende a identificarse más con la materia que con el espacio inteligible de la tradición de ascendencia judaica. (cf. Giancotti, E.: Studi su Hobbes e Spinoza, Napoli, Bibliopolis, 1995, p. 100).

44 E, I, 15,schol. (Geb. II, 57) (62-63).
} 
pié, aparecen dos nociones de cantidad o materia, y, al menos en uno de estos sentidos, se puede decir que Dios es material. Dios es materia; no sólo materia, pero es materia.

La materia, o la cantidad, que es la misma en todo lugar, puede concebirse de dos formas: o con la imaginación o con el entendimiento. En el primer caso, la materia aparecerá finita, divisible y compuesta de partes. En el segundo caso, cuando concebimos a la materia, en cuanto atributo (en tanto Natura naturans), entonces necesariamente aparecerá infinita, única e indivisible. En este caso, es decir, cuando concebimos a la materia con el entendimiento, puede ser atribuida a Dios. Es más, incluso aunque no fuese así, y la materia fuese divisible y se compusiese de partes (que es el argumento en el que se amparan los adversarios para negar que pueda atribuirse a Dios), "no sé por qué -señala Spinoza- la materia sería indigna de la naturaleza divina, supuesto que no puede darse fuera de Dios sustancia alguna por la que pueda padecer." 45 Es decir, que lo que a Spinoza le parece una condición irrenunciable para atribuir materialidad a Dios, es que la materia sea infinita y eterna. Puede renunciar a la condición de la divisibilidad, pero no a éstas. De este modo, lo que sí excluye necesariamente de la naturaleza divina es, una vez más, la pasión. Y ello me parece especialmente relevante porque, además de poner de manifiesto de otra forma que Dios no padece y que esto le parece a Spinoza una verdad tan firme que es el único argumento que él consideraría lo suficientemente fuerte como para excluir la materia de la naturaleza de Dios, muestra, al mismo tiempo, otra tesis que es importante para entender qué tintes tiene el naturalismo spinoziano. Me refiero al vínculo profundo que existe entre pasión y finitud en la filosofía de Spinoza y que se expresa aquí, indirectamente, a través de la relación que Spinoza establece entre infinitud y ausencia de padecimiento. Es la infinitud de la Sustancia la que le imposibilita padecer. Si la materia es infinita, Dios no puede padecer. Ésa es la idea que está en el trasfondo del argumento de Spinoza en el escolio antes citado.

No obstante, el hecho de que la materia infinita excluya el padecimiento no quiere decir que entre materia y pasión no haya relación posible. La cuestión es que hay una materia que, en virtud de su infinitud y eternidad, no padece nunca. Pero hay otra materia, la finita, la que tiene que ver con el cuerpo propiamente dicho, que no sólo no excluye la pasión, sino que encuentra en ella una expresión fundamental. Spinoza pone de manifiesto en su Ética que tenemos pasiones porque tenemos cuerpo; y somos pasión, porque somos cuerpo. En el libro III de la Ética las pasiones, es decir, los afectos pasivos, son definidas como las afecciones del cuerpo, por las cuales aumenta o disminuye la potencia de obrar de ese mismo cuerpo, y, al mismo tiempo, como las ideas de esas afecciones. ${ }^{46}$ Pero será en el libro V donde se reconozca de manera más clara este nexo indisoluble entre cuerpo y pasión. "El

45 E, I, 15,school. (Geb. II, 60) (67).

46 Cf. E, III, def. III (Geb. II, 139) (193). 
alma -señala allí Spinoza- no está sujeta a los afectos comprendidos dentro de las pasiones sino mientras dura el cuerpo." 47

Hasta aquí se ha intentado determinar cuáles son las características de la Natura naturans que son más relevantes desde el punto de vista del objeto de este estudio. Sin embargo, ya sabemos que la Naturaleza naturante es sólo una de las dos perspectivas de lo real que distingue Spinoza. Hay que analizar, pues, también los rasgos que presenta lo real cuando se expresa como Natura naturata.

\subsection{Natura naturata: la condición de ser parte}

En cuanto a la naturaleza de los modos, ésta será de una manera o de otra, dependiendo de aquello en virtud de lo cual se sigan de Dios. Así se establece la distinción entre modos infinitos y modos finitos, ambos "productos" de la Sustancia, ambos afecciones de su naturaleza. Ahora bien, a pesar de que los modos son afecciones de la Sustancia por las cuales ésta expresa su naturaleza de cierta y determinada manera ${ }^{48}$, las características de ambos son bastante diferentes. Ésta es, como ya se ha señalado, una de las principales razones que pueden esgrimirse para preferir el uso del término "naturalismo" al término "panteísmo" para caracterizar la concepción del mundo que nos presenta Spinoza. Todo no es Dios. Los modos no son Dios, no son Sustancia. No comparten todas sus propiedades o rasgos.

Los modos no tienen una esencia que implique necesariamente su existencia, es decir, no son causa sui. En este sentido, los modos son contingentes. Hay que tener en cuenta que Spinoza distingue dos sentidos de contingencia en la Ética. En el libro I identifica lo contingente con lo posible y opone a éstos lo necesario, tanto en razón de la esencia, como en razón de la causa. Y ello porque "la existencia de una cosa cualquiera se sigue necesariamente, o bien de su esencia y definición, o bien de una causa eficiente dada." 49 Pues bien, tanto en un caso como en otro, lo necesario se opone a lo contingente o posible, ya que atañe al ser de las cosas, mientras que lo contingente o posible sólo se refiere a nuestro modo de conocerlas. De este modo, Spinoza llama contingente o posible a una cosa "de cuya esencia ignoramos si implica contradicción, o de la que sabemos bien que no implica contradicción alguna, pero sin poder afirmar nada cierto de su existencia, porque se nos oculta el orden de las causas." 50 Contingente y posible son, pues, sinónimos en el libro I, y ambos atañen a una deficiencia de nuestro conocimiento. De ahí la consecuencia que deduce Spinoza, esto es, que en la naturaleza no hay nada contingente. 51

\footnotetext{
47 E, V, 34 (Geb. II, 301) (417).

48 Cf. E, I, 25, corol. (Geb. II, 68) (80).

49 E, I, 33, school. I (Geb. II, 74) (89-90).

50 E, I, 33, schol. I (Geb. II, 74) (89-90).

51 "En la naturaleza no hay nada contingente, sino que en virtud de la necesidad de la naturaleza divina, todo está determinado a existir y obrar de cierta y determinada manera" E, I, 29 (Geb. II 70) (83).
} 
Sin embargo, en el libro IV Spinoza va a distinguir entre lo contingente, que atañe a la esencia de las cosas, y lo posible que atañe a las causas y que no es sino un defecto de nuestro conocimiento. Y así, en la definición III del libro IV, Spinoza señala que contingentes son las cosas singulares, en cuanto que, "atendiendo a su sola esencia, no hallamos nada que afirme o excluya necesariamente su existencia." 52 Lo contingente se opone así a lo necesario como el modo se opone a la Sustancia o causa sui. Sin embargo, se llama posibles a "esas mismas cosas singulares, en cuanto que, atendiendo a las causas en cuya virtud deben ser producidas, no sabemos si esas causas están determinadas a producirlas." 53 Lo posible alude sólo a nuestra manera de concebir las cosas, en concreto, a nuestro desconocimiento de sus causas y, por tanto, se opone a lo necesario en la medida en que este término atañe a la esencia de las cosas y no sólo a nuestra manera de concebirlas. Sin embargo, lo que quiero subrayar es que, si nos atenemos a esta distinción entre lo contingente y lo posible, y a la definición que de lo contingente Spinoza nos ofrece en el libro IV, entonces, en la naturaleza sí hay algo contingente, a saber, los modos finitos. La Natura naturans o Dios no es contingente en ningún sentido; en cambio, la Natura naturata o los modos sí son contingente en el sentido de que no son causa sui, es decir, su esencia no implica necesariamente su existencia. 54

Otra de las diferencias entre la Sustancia y los modos consiste en que la determinación a obrar de los modos no depende de ellos mismos, sino de Dios 55 , es decir, los modos no son libres. Siguiendo la definición de la libertad que Spinoza nos ofrece al principio de la Ética, se podría decir que el modo se opone a la Sustancia como lo compelido o determinado por otro se opone a lo libre o determinado por sí.

Los modos son dependientes. En este sentido, A. Matheron habla del contrato existencial de las esencias singulares. ${ }^{56}$ Sólo en virtud de este contrato, pueden existir. El estado "naturado" de las esencias se caracteriza por la contradicción que les afecta entre la necesidad de ser y la dificultad de ser. Esta contradicción se puede resolver. Pero es necesario recurrir a un nuevo tipo de causalidad. Lo que le falta para existir a la esencia singular, lo va a recibir del exterior; también de Dios, pero esta vez indirectamente, esto es, de Dios, no en tanto que se manifiesta en ella como su naturante interna, sino en tanto que se manifiesta en las otras esencias singulares. 57

52 E, IV, def. III (Geb. II, 209) (288).

53 E, IV, def. IV (Geb. II, 209) (288).

54 De este modo, Spinoza afirma claramente en el libro II que "la esencia del hombre no implica la existencia necesaria, esto es: en virtud del orden de la naturaleza, tanto puede ocurrir que éste o aquel hombre exista como que no exista. E, II, axioma I (Geb. II, 85) (111). En conclusión, no hay nada contingente en la Natura naturans, pero sí en la Natura naturata. El hombre, una vez que existe, es necesario como opuesto a posible, pero no a contingente. Para un análisis detallado de los dos sentidos de contingencia que distingue Spinoza, véase el excelente trabajo de Ávila, R.: "Finalidad, deseo y virtud: Spinoza y Nietzsche”, Anales del Seminario de Metafísica, 20, 1985, pp. 24-25.

55 E, I, 26 y 27 (Geb. II, 68) (80).

56 Matheron A. : op. cit., p. 20.

57 Cf. Loc. cit., p. 18. 
Una doble conclusión se impone. Para las cosas singulares resultan vitales las relaciones con los otros modos, a diferencia de la Sustancia que es autosuficiente. Los individuos singulares no pueden existir más que en comunidad, a título de partes de un Universo infinito en el seno del cual todo actúa sobre todo. Sólo esta interacción universal por la cual se compone mutuamente un contexto favorable explica Matheron- puede permitir a cada uno de ellos, aportándole desde fuera la infinidad de determinaciones que no posee por naturaleza, llenar el vacío lógico que le impedía actualizarse. 58

En segundo lugar, otra de las características de la Natura naturata, que no comparte con la Natura naturans, y que está asociada con esta no autosuficiencia de los modos, tiene que ver específicamente con la cuestión de las pasiones. Antes se ha citado la proposición 31 del libro I de la Ética según la cual el entendimiento en acto, sea finito o infinito, así como la voluntad, el deseo, el amor, etc., deben ser referidos a la Naturaleza naturada, y no a la naturante. 59 Sólo a nivel del modo puede, por tanto, hablarse de afectos, y aún más, de pasiones. Las pasiones tendrán que ver fundamentalmente con los modos finitos, con lo que es siempre una parte de la Naturaleza y nunca el Todo, con aquello que necesita relacionarse con otros modos finitos para subsistir. Sólo el hombre, en tanto modo finito, puede desear, alegrarse y entristecerse. ${ }^{60}$ Dios no puede padecer. Sólo en lo finito hay padecimiento. De nuevo, vuelve a ponerse de manifiesto el vínculo tan estrecho que Spinoza encuentra entre finitud y pasión.

Estrictamente relacionado con el padecimiento, está también la moral. Sólo en lo finito tendrá sentido la moral. El Bien y el Mal, tal y como decía antes, no son propiedades de la Naturaleza en cuanto Natura naturans. Dios es inocente, es decir, es amoral. No hay Bien ni Mal en él. Ahora bien, en el ámbito de la Natura Naturata, y en relación al hombre, no todo está bien como está. Las cosas, no en sí mismas, sino en relación con ese modo finito que es el hombre, pueden ser buenas o malas, mejores o peores. Será, pues, en el ámbito de la Natura naturata, y, en particular, en el ámbito humano, donde habrá espacio para la reflexión sobre las pasiones y para la moral.

En definitiva, después de este recorrido por la ontología de Spinoza, tal y como ésta queda expuesta en el libro I de su Ética, y especialmente tras mostrar las diferentes características que tienen Dios y los modos, se puede afirmar que la ontolo-

\footnotetext{
58 Cf. Loc, cit., pp.19-20.

59 Cf. E, I, 31 (Geb. II, 71) (85).

60 "Padecemos - señala Spinoza- en la medida en que somos una parte de la naturaleza que no puede concebirse por sí sola, sin las demás partes.” E, IV, 2 (Geb. II, 212) (291). Y “es imposible que el hombre no sea una parte de la naturaleza, y que no pueda sufrir otros cambios que los inteligibles en virtud de su sola naturaleza, y de los cuales sea causa adecuada.” E, IV, 4, (Geb. II,212 ) (292).
} 
gía de Spinoza es naturalista en la medida en que es el término "Naturaleza" el que expresa de manera más completa lo real spinoziano. A diferencia de Dios, que es lo real en tanto infinito, causa sui, libre, etc., pero no es, propiamente, lo real en tanto finito, compelido, etc. aunque se exprese en ello, la Naturaleza es también lo real en tanto modo, esto es, es también aquel otro aspecto de lo real que no es necesariamente infinito, que no es de existencia necesaria, ni causa de sí mismo, que es heterónomo, pasional, moral, etc.. Es el término "Naturaleza" el que elige Spinoza para expresar, adjetivando este nombre, los dos aspectos que se pueden distinguir en la realidad. Es cierto que los modos, sin la Sustancia, no tienen ninguna realidad. Y que la Sustancia, considerada independientemente de sus modos, es solo una abstracción. Tal y como acertadamente observa A. Matheron, es contradictorio hipostasiar la actividad separándola de sus estructuras. ${ }^{61}$ Ahora bien, sigue siendo cierto que aunque los modos no sean sin la Sustancia, y ésta sólo sea una abstracción sin los modos, no comparten su ser. Los modos son en la Sustancia; pero no son Sustancia. Y la Sustancia se expresa en los modos, pero no es un modo. Sin embargo, sí se puede decir que la Naturaleza es Sustancia y que la Naturaleza es modo, pues ésta es tanto naturante como naturada. La Naturaleza se adjetiva de estas dos formas. Es una y múltiple. En virtud de su plenitud, contiene la diversidad en su seno.

Además, la Naturaleza no se define expresamente en ninguna de las partes de la Ética. No hay definición explícita de Naturaleza, como sí la hay de Dios o de la Sustancia. Tampoco la Naturaleza aparece definida en algunas de las proposiciones o demostraciones. Y, sin embargo, ella está presupuesta en casi todas ellas. De este modo, podría decirse que la Naturaleza es un término trascendental en la ontología de Spinoza. Ella misma no se define y no se demuestra, pero está presupuesta en la mayoría de las demostraciones. Atraviesa proposiciones, escolios y corolarios de todas las partes de la Ética, sean de carácter ontológico o práctico. También desempeña un lugar destacado en las primeras obras de Spinoza y sigue jugando un papel importante en sus obras políticas. Por todo ello el término "naturalismo" parece bastante adecuado para caracterizar la visión del mundo que nos presenta Spinoza.

No obstante, además de concebir lo real como Naturaleza, había otros dos requisitos más que debían cumplirse para poder hablar de naturalismo. Pues bien, también la ontología de Spinoza satisface ambas condiciones.

\section{Inmanencia y desengaño}

En primer lugar, el carácter antitrascendentista o antisobrenaturalista que se atribuye al naturalismo también se observa en la reflexión spinoziana. La defensa radi-

61 Cf. Matheron, A.: op. cit., p. 21. 
cal de la inmanencia es una de las características más destacables de la ontología de Spinoza.

"Quicquid est, in Deo est, et nihil sine Deo esse, neque concipi potest."62 Del monismo ontológico se sigue que todo lo que es, tiene que ser en la Sustancia. Todo se da en ella y se sigue de ella. Ahora bien, ¿cómo tiene lugar este "darse en” o este "seguirse de"? La causalidad es la clave definitoria de ese proceso, pero se trata de una causalidad peculiar. En primer lugar, es causalidad eficiente y no final. También es causalidad libre, en el sentido determinado en que se ha dicho que puede ser libre la Naturaleza, la Sustancia o Dios. Pero entre todas las características de la causalidad spinoziana, hay algunas que son especialmente relevantes para el propósito de este estudio, esto es, es especialmente digno de mención que se trate de una causalidad inmanente y expresiva de la potencia.

Spinoza señala sin ambages que "Deus est omnium rerum causa immanens; non vero transiens."63 De la tesis de que solo hay una Sustancia o Dios, se sigue que Dios ya no puede crear las cosas desde fuera, como si fuese una entidad trascendente, ni puede constituir otro mundo, separado del nuestro, que serviría de modelo para el más acá de las criaturas. Dios se ha vuelto inmanente. Es Naturaleza, Naturaleza naturante, y entonces, no crea, sino que se expresa. Produce, pero lo hace expresándose de forma inmanente en el resto de cosas, que son expresiones suyas y no criaturas.

El proceso de expresión es, además, un proceso de expresión de la propia naturaleza de Dios, y, puesto que ésta no es otra cosa que potencia, aquél no es sino un proceso de expresión de potencia. Así lo confirma la demostración de la proposición 36 donde se dice claramente que "todo cuanto existe expresa la naturaleza, o sea, la esencia de Dios de una cierta y determinada manera, esto es, todo cuanto existe expresa de cierta y determinada manera la potencia de Dios, que es causa de todas las cosas"64. Los modos serán una expresión de la potencia divina. "Res particulares nihil sunt, nisi Dei attributorum affectiones, sive modi, quibus Dei attributa certo, et determinato modo exprimuntur." 65 De hecho, la distinción entre Natura naturans y Natura naturata es la distinción que se establece entre lo que se está expresando y lo expresado. La Natura naturans se refiere a la Naturaleza que se está expresando, a la Naturaleza como flujo continuo. Eso es lo que señala el participio de presente "naturans". La Natura naturata, en cambio, se refiere a lo expresado, a aquello en que se va plasmando aquel flujo continuo. Así lo muestra el participio "naturata" como participio pasado. Entre Natura naturans y Natura naturata no hay, pues, hiato, sino prolongación. Y tal prolongación, el punto de encuentro entre lo que se expresa y lo expresado, reside en la potencia.

62 E, I, 15 (Geb. II, 56) (62).

63 E, I, 18 (Geb. II, 63) (73).

${ }^{64}$ E, I, 36, dem. (Geb., II, 77).

65 E, I, 25, corol. (Geb. II,68) (80). 
En conclusión, Spinoza concibe la relación entre la Naturaleza naturante y la Naturaleza naturada como un proceso de expresión inmanente de potencia. Dios es causa inmanente y no trascendente de las cosas. Así lo ha afirmado claramente el filósofo. Los modos están en Dios y Dios está también en los modos. La inmanencia es doble y no hay exterioridad ninguna. Dios no es exterior a los modos, ni a los infinitos ni a los finitos, aunque los desborde si los tomamos aisladamente; ni los modos son exteriores a Dios. No hay aquí instancia trascendente alguna. Ni Dios está más allá de los modos, ni los modos más acá de Dios. No hay un mundo más allá de este mundo. Ese más allá, es una ficción, una ilusión alienante.

Además, esta ontología de la inmanencia supone una ruptura con la metafísica creacionista. Dios no es ya el Dios creador del judeo-cristianismo. No hay aquí creación propiamente dicha porque ésta implica la existencia de dos sustancias distintas, una de ellas trascendente a la otra. Dios no es trascendente, sino inmanente a las cosas y, por tanto, más que de creación, hay que hablar de expresión.

En suma, se ha subvertido el concepto tradicional de Dios creador (crítica a la trascendencia), personal (crítica al antropomorfismo) y juez (crítica a la concepción absolutista del Bien/Mal), corrigiendo ese largo error que compromete a la ontología entera66, a través de un nuevo concepto, el propiamente spinoziano, de un Dios que se ha vuelto Naturaleza. De ahí que el naturalismo vuelva a aparecer como un buen concepto para calificar a la ontología spinoziana en lo que tiene de más original.

Y así también, y, en último lugar, encontramos en el pensamiento de Spinoza aquel tercer rasgo propio de la actitud naturalista, que tiene que ver con la empresa, filosófica por excelencia, de la desilusión o del desengaño. Numerosos son los desengaños que provoca la filosofía spinoziana. A propósito del libro I de la Ética, hemos visto cómo se combaten todos aquellos prejuicios que se esconden tras una mala comprensión de la Naturaleza y que son fundamentalmente el teleologismo y el antropomorfismo. Hemos visto también cómo Spinoza subvierte el concepto tradicional de Dios, personal, creador y trascendente, a través de un nuevo concepto de Dios, de un Dios que se ha vuelto Naturaleza. La ilusión del Bien y del Mal como propiedades de la naturaleza y, así, como valores objetivos y absolutos, u otras como la de la voluntad libre, quedan corregidas cuando son contempladas con la lente de Spinoza. 67

En conclusión, puede afirmarse que la ontología de Spinoza es naturalista porque satisface los tres requisitos para ser tal, a saber, mantiene que lo real es

\footnotetext{
66 Deleuze, G.: Spinoza: filosofia práctica, ed. cit.,p. 35.

67 En este mismo sentido, señala Espinosa Rubio que el naturalismo es negador de toda una visión de mundo, de una red de quimeras y palabras sustantivadas, de prejuicios y supersticiones, de efectos y racionaliaziones. El naturalismo "se opone al apoyo capital que la figura de Dios sigue prestando al antropomorfismo en la filosofía moderna y a todas sus consecuencias de heteronomía teórica y práctica." (Espinosa Rubio, L: op. cit. p. 20).
} 
Naturaleza, y desde esta concepción, combate toda forma de mistificación, y fundamentalmente aquella que nos presenta lo real como algo sobrenatural, sea cual sea el rostro que esto sobrenatural presente. Ahora bien, dentro de esta actitud naturalista general, caben muchas variedades. Todo materialismo es naturalista, pero la inversa no es cierta, por ejemplo. Y así, es conveniente, en favor de la concreción y precisión, plantear la cuestión de qué tipo de naturalismo es el propiamente spinoziano. ¿Qué adjetivo lo delimita mejor? ¿Cuáles son los rasgos propios de este naturalismo ontológico?

\section{Naturalismo dinámico y de carácter materialista}

La primera característica que se pone de manifiesto cuando reflexionamos sobre las observaciones que Spinoza hace en la primera parte de la Ética sobre la causa sui, la Sustancia, los atributos y los modos, y, en definitiva, sobre la Naturaleza, es el dinamismo. ${ }^{68}$ La ontología de Spinoza es una ontología dinámica, y de este modo, también su naturalismo. Y ello resulta bastante novedoso porque no se renuncia en ella al concepto de Sustancia. Sin embargo, ésta ha sido una de las categorías que tradicionalmente ha usado la metafísica para concebir la realidad de modo fijo y estático. Spinoza, en cambio, conserva el término, pero le da un nuevo sentido.

En lo referente a la Sustancia, ya sabemos que es lo único que es causa sui y que en el mismo sentido en que es causa de sí, es causa de todo lo que hay. La Sustancia, y con ella la Naturaleza, produce como existe. La producción es un proceso espontáneo que le es natural. Por eso dice Spinoza que Dios es causa por sí y no por accidente de todas las cosas. ${ }^{69}$ Pero la fórmula más adecuada para entender este proceso de expresión no es la clásica e inerte ecuación $\mathrm{A}=\mathrm{A}$, sino más bien la relación que se representa con la expresión "A hace que a llegue a ser a."70 Esta

\footnotetext{
68 En este aspecto, destacan, entre otros, los trabajos de J. García Leal y A. Matheron. La tesis de García Leal es que la ontología de Spinoza corrige su propia teoría física, rompiendo con el estatismo de los cuerpos a que aboca el modelo mecanicista, y considerando la materia dinámicamente, animada internamente por un movimiento del que se derivan todos los cuerpos, no como seres estancos y quietos, sino como efectos necesarios de un dinamismo común, partícipes ellos mismos de tal dinamismo. (cf. García Leal, J.: "Física y ontología en Spinoza", Revista de Filosofia, 8, 1985, pp. 253 280.) También Matheron reconoce el dinamismo propio de la ontología spinoziana y, en este sentido, señala que todo individuo debe presentarse realmente bajo dos aspectos complementarios y recíprocos: una actividad productora y el resultado de esta actividad. La productividad pura sería la Sustancia; las estructuras que se dan en su desarrollo, los modos; y la manera en que la Sustancia produce sus propias estructuras, los atributos. (Cf. Matheron, A., op. cit., p. 11).

${ }^{69}$ Cf. E, I, 16, corol. II (Geb. II, 61) (68) (52).

70 Sigo aquí la explicación de E. Fernández, pero he modificado levemente la ecuación que él propone. Y así, en lugar de "A pone a A", o bien, "A hace que A llegue a ser A", escribo "A hace que a llegue a ser a" para reflejar la diferencia que hay, tal y como he argumentado, entre la Natura naturans
} 
relación ya no es estática, sino dinámica. Además, si la producción así entendida es algo propio de la Sustancia, ésta no es ya un sustrato fijo que soporta firmemente el peso de la realidad, ni un sujeto del que se prediquen todas las cosas. La Sustancia es fundamento, pero no estático sino dinámico, y su consistencia reside en su capacidad para emerger y hacer emerger. ${ }^{71}$

Así pues, como muchos intérpretes de la filosofía de Spinoza han puesto de manifiesto, la radicalización de la Sustancia que lleva a cabo el filósofo pone fin al sustancialismo. 72 Éste es un engaño de quienes en vez de concebir la naturaleza de la Sustancia, la imaginan al modo de las cosas. A los ojos de la razón, en cambio, ese fenómeno de cosificación es resultado de una confusión de imágenes que da lugar a los términos trascendentales "ente" y "cosa". La crítica spinozista de los trascendentales, tal y como aparece en el escolio de la proposición 40 de la segunda parte de la Ética, es también una crítica al sustancialismo, es decir, una crítica por la que se disuelve la ontificación de la Sustancia y se descubre su auténtica naturaleza móvil, dinámica y activa. 73

No obstante, el argumento central que puede esgrimirse para probar el carácter dinámico del naturalismo spinoziano se basa en la consideración de la potencia de existir y obrar como esencia de la Naturaleza, y del proceso de producción como un proceso de expresión de esa potencia.

La potencia, como ya se advirtió en el análisis de la primera parte de la Ética, hay que entenderla en el sentido de vigor y de fuerza, de dynamis y de vis, para existir y no para dominar. Y así la potencia no es equivalente al poder. Ahora bien, lo que interesa resaltar aquí es que la potencia define no sólo a la Natura naturans, donde tiene lugar en grado sumo, sino también a la Natura naturata. Y así, el conatus con el que toda cosa singular, incluido el hombre, se esfuerza por perseverar en su ser, es también potencia; aunque en este caso, potencia finita ${ }^{74}$. La potencia es, pues, el verdadero constitutivo de lo real. 75 En conclusión, la ontología de Spinoza es una ontología dinámica en tanto que ontología de la potencia. Además, la elevación de la potencia al rango de ser tiene una serie de consecuencias que hay que considerar para completar la caracterización de la reflexión ontológica de Spinoza y así de su naturalismo.

y la Natura naturata. Cf. Fernández, E.: Potencia y razón en B. Spinoza, Madrid, Editorial de la Universidad Complutense de Madrid, 1987, p. 253.

${ }^{71}$ Loc. cit., p. 254.

72 Véanse a este respecto Currás, A.: "La doble articulación del discurso en la Ethica de Spinoza: tarea crítica y proyecto liberador", Anales del Seminario de Metafísica, 10, 1975, pp. 7-62; Fernández, E.: op. cit.; Misrahi R.: Spinoza, Madrid, E.D.A.F., 1975 [Trad. F. L. Castre]; Vidal Peña, El materialismo de Spinoza, Madrid, Revista de Occidente, 1974. Por sustancialismo entendemos la concepción de la realidad como una sustancia hierática, fija y estática.

73 Cf. Fernández, E.: op. cit., p. 255.

74 Cf. E, III,7, dem. (Geb. II, 146) (204).

75 Cf. Fernández, E.: op. cit., pp. 454-457. 
En primer lugar, la ontología de la potencia es también una ontología de la razón. En este sentido, E. Fernández señala que "hablar de potencia y de razón es una reduplicación; pero eso significa no que la razón sea el doble, el reflejo narcisista de la potencia, sino que es su desenvolvimiento, la capacidad de mirar y reconocer a los otros que acompaña a su dinámica de multiplicación y que permite a cada uno actuar de forma espontánea, pero ya no ciega ni excluyente, sino lúcida, coordinada y mutuamente potenciadora." 76

En segundo lugar, la ontología de la potencia abre el espacio también para la pasión, pues también las pasiones son potencias. El deseo, que es el afecto primero por excelencia, es una forma de conatus, esto es, del esfuerzo, esto es, de la fuerza con la que cada cosa persevera en su ser ${ }^{77}$. La alegría y la tristeza son, además, expresión o represión de potencia, conatus favorecido o coartado 78 .

Por otra parte, del dinamismo y de la potencia como propiedades de la ontología de Spinoza se deduce que ésta es una ontología de la expresión. El proceso de producción que lleva a cabo la Sustancia es un proceso, tal y como se vio en su momento, expresivo de la potencia divina. La expresión tiene lugar en dos niveles: el nivel del atributo y el nivel del modo ${ }^{79}$. En cuanto a éste último, la idea de expresión está estrechamente relacionada con la de afección. Y así los modos no son sino afecciones de algún atributo de Dios, en los que se expresa su naturaleza de cierta y determinada manera. La idea de afección, además, permite poner de manifiesto otros dos rasgos de la ontología de Spinoza.

En primer lugar, ésta es una ontología relacional. El dinamismo expresivo de la Sustancia en atributos y modos hace de la Natura naturans "un juego de relaciones" 80 . Y en el plano de los modos, y, en concreto, del hombre, la importancia que para ellos cobra el afectar y el dejarse afectar por otros, hace del relacionarse una necesidad vital. 81

\footnotetext{
76 Loc. cit., p. 502.

77 Spinoza llama apetito al conatus referido al cuerpo y al alma. Pero "entre apetito y deseo no hay diferencia alguna, si no es la de que el deseo se refiere generalmente a los hombres en cuanto que son conscientes de su apetito, y por ello puede definirse así: el deseo es el apetito acompañado de la conciencia del mismo." E, III, 9, schol. (Geb. II, 147-148) (205-206).

78 "La tristeza -afirma Spinoza- disminuye o reprime la potencia de obrar del hombre, esto es, disminuye o reprime el esfuerzo que el hombre realiza por perseverar en su ser, y, de esta suerte es contraria a ese esfuerzo; (...) la alegría aumenta o favorece la potencia de obrar del hombre" E, III, 37, dem. (Geb. II, 168-169) (234-235).

79 Cf. Deleuze, G.: Spinoza y el problema de la expresión, Barcelona, Muchnik, 1975, pp. 9-19, especialmente, 9-10. [Trad. H. Vogel]

80 Fernández, E.: op. cit., p. 267.

81 "Nosotros - señala Spinoza- no podemos prescindir de todo lo que nos es externo para conservar nuestro ser, y no podemos vivir sin tener algún comercio con las cosas que están fuera de nosotros" (E, IV, 18, schol. (Geb. II, 222-223) (306-307).
} 
En segundo lugar, la afección tiene un aspecto extenso o material que hay que considerar. La Sustancia tiene sus afecciones: los modos. Y los modos mismos son modos del atributo Pensamiento y también del atributo Extensión. En este sentido, si nos fijamos en la Extensión de la Sustancia y, en segundo lugar, en los modos de este atributo, se puede encontrar cierto materialismo en la ontología de Spinoza. Y así, algunas de las interpretaciones más actuales, pero también más antiguas de su filosofía han coincidido en señalar este rasgo. 82

Uno de los primeros en poner de manifiesto, en un sentido crítico, el carácter materialista de la filosofía de Spinoza, fue P. Bayle. En el artículo Spinoza, de su Dictionnaire historique et critique, Bayle afirma que es absurdo hacer de la Extensión un atributo divino, pues la materia, según arguye, es el más bajo de todos los seres. Quien dice materia dice el teatro de toda suerte de cambios, sujeto de todas las corrupciones y generaciones; "en un mot l'être dont la nature est la plus incompatible avec l'immutabilité de Dieu." 83 De este modo, Spinoza, al hacer de la Extensión un atributo divino, subvierte de tal forma el concepto de Dios, que termina por negarlo. Y así, a partir de ese momento, la filosofía de Spinoza será el "sistema del ateísmo", interpretación que pasa, a la Enciclopedia de Diderot y D'Alembert, sin corrección. ${ }^{84}$

Más tarde, L. Feuerbach encuentra en Spinoza la verdadera expresión filosófica de la tendencia materialista de la edad moderna. La filosofía spinoziana es el materialismo teológico. 85 Finalmente, en los estudios de las últimas décadas, se ha hecho hincapié en que si bien no hay en la filosofía de Spinoza exclusividad materialista, sí pueden hallarse en ella elementos para la construcción de una concepción materialista del mundo y del hombre. 86

\footnotetext{
82 Véanse a este respecto Ávila, R.:,op. cit.; Giancotti, E.: op. cit.; Gurméndez, C.: Ontología de la pasión, México, Fondo de Cultura Económica, 1996; Jaquet, Ch.: op. cit.; Negri, A.: op. cit.; Vidal Peña: El materialismo de Spinoza, ed. cit..

83 Bayle, P.: Dictionnaire historique et critique, Vol II, Rotterdam, 1715, p. 618.

84 Cf. Giancotti, E.: op. cit., p. 98. Para una interesante reflexión en torno a Spinoza como patrón del ateísmo moderno, véase De la Cámara, M. L.: "Samuel Clarke contra Spinoza: la imagen de un adversario", Cuadernos del seminario Spinoza, 11, 2000, pp.1-25).

85 Cf. Feuerbach, L.: Grundsätze der Philosophie der Zukunft, § 23. Junto a estas interpretaciones materialistas, habría que mencionar las no materialistas. Así, por ejemplo, Marx ve todavía en Spinoza un vestigio de la metafísica y un lenguaje teológico que vuelve difícil liberar la verdad que en Spinoza puede estar contenida. Esto justifica el juicio severo expreso de Marx y Engels en la Sagrada Familia, y en la Ideología alemana, y según el cual Spinoza está entre los representantes de la metafísica del siglo XVII contra los cuales han luchado el Iluminismo y el materialismo francés del XVIII. (cf. Giancotti, E.: op. cit., pp.57-58).

86 En este sentido, es especialmente relevante la obra E. Giancotti, a la que se ha hecho referencia antes. También Ch. Jaquet considera que es legítimo asimilar la concepción spinoziana del cuerpo a un materialismo a condición de entender este concepto como un principio de inteligibilidad de lo real fundado sobre el atributo extensión. Y a condición también de que el discurso materialista no se erija en norma exclusiva de inteligibilidad de lo real, puesto que la Sustancia una y única tiene una infini-
} 
De estos elementos "materialistas" del spinozismo, destaca, sobre todo, la concepción de la Extensión como atributo divino con la misma dignidad ontológica que el Pensamiento ${ }^{87}$. Es cierto que no puede afirmarse absolutamente que la ontología spinoziana y, con ella, el naturalismo, sea materialista porque la Extensión es sólo uno de los infinitos atributos de Dios, mientras que el materialismo mantiene que la materia es toda la realidad y cada fenómeno es, incluido el conocimiento, reconducible a ella como a su causa. Para el materialismo es el ser material el que determina el pensamiento, mientras que para el spinozismo es el Ser, cuya realidad supera la materia, el que se autodetermina determinando toda la actividad del pensamiento y de la extensión según un orden idéntico. ${ }^{88}$ Pero a pesar de que el materialismo no es norma exclusiva de inteligibilidad de lo real, sí se puede afirmar que, a partir de la atribución de igual dignidad ontológica a la Extensión y al Pensamiento, la filosofía de Spinoza combate ciertos prejuicios espiritualistas que habían llevado a cierta tradición filosófica, a la cartesiana más recientemente, a una condena de la materia como ser indigno de la naturaleza divina, y que, en esa medida, puede encontrarse en la ontología spinoziana cierto materialismo. Lo que nos viene a decir Spinoza es que la materia tiene, como mínimo, el mismo valor ontológico que el pensamiento, que el Ser es tan material como ideal. De este modo, puede decirse que el naturalismo de Spinoza encuentra en este elemento materialista de su pensamiento un asociado fundamental, de manera que puede afirmarse, con los matices antes señalados, que es un naturalismo materialista, aunque no reduccionista.

Tanto es así que tal "dignidad ontológica" alcanza también al cuerpo propiamente dicho, es decir, a un modo finito de la Extensión. Es cierto que Spinoza crítica a todos aquellos que, alejados de un verdadero conocimiento, se representan a Dios como un compuesto de cuerpo y alma. Dios no tiene cuerpo al modo de los hombres; aunque lo mismo puede decirse del alma. Al cuerpo le ocurre lo mismo que a la voluntad y al entendimiento, es decir, que es un modo y no un atributo de Dios. De este modo, si el cuerpo, lo mismo que el entendimiento y la voluntad, perteneciese a la esencia de Dios considerada en sí misma, entonces habría de enten-

dad de expresiones (Cf. Jaquet, Ch.: op. cit., pp. 211-215, especialmente, p. 213). En este sentido, la objeción que plantea Gueroult para interpretar en un sentido materialista el naturalismo de Spinoza no es válida. Gueroult afirma que no hay naturalismo materialista en la filosofía de Spinoza porque la Naturaleza, con la cual Dios se identifica, no es la materia, sino que comprende en su unidad indivisible, además de la Extensión, una infinidad de otros géneros de ser. (cf. Gueroult, M.: op. cit, p. 223.) Sin embargo, tal y como trato de argumentar, ello no supone un problema para defender que hay ciertos elementos materialistas en la filosofía de Spinoza.

87 Junto con este elemento materialista sobre el que aquí hago hincapié, E. Giancotti destaca otros tres más: en primer lugar, la independencia de los atributos, de modo que puede decirse que la materia es independiente del pensamiento; en segundo lugar, la concepción del hombre como parte de la Naturaleza; y en tercer lugar, la concepción de la libertad como comprensión de la necesidad. (cf. Giancotti, E.: op.cit. pp.95-120.)

${ }^{88}$ Loc. cit., p. 114. 
derse por cuerpo algo distinto de lo que ordinariamente entienden los hombres. La Extensión debería concebirse, pues, más que como cuerpo, como materia indivisible e indisociablemente unida a la infinitud, a la eternidad y a la ausencia de padecimiento. El cuerpo, en cambio, como materia, pero divisible, compuesta de partes, e indisociablemente unida a la finitud y al padecimiento. ${ }^{89}$ No obstante, el cuerpo no pierde su valor ontológico, y, en todo caso, goza de la misma relevancia ontológica que el alma. Y si esto es así, es precisamente porque la Natura naturans es extensa.

Así pues, este elemento materialista de la ontología es condición de posibilidad de lo que luego va a desarrollar Spinoza en los libros II y III de la Ética, y que podría denominarse su "filosofía del cuerpo". En los libros II y III se señala en repetidas ocasiones que conocer la naturaleza de los cuerpos es un requisito indispensable para conocer el alma y, en definitiva, para conocer la realidad; y que determinar lo que puede un cuerpo por sí mismo es una tarea, hasta ahora no lograda en la historia de la filosofía, y que, sin embargo, es urgente realizar90. De este modo, Spinoza, en la línea después seguida por Schopenhauer, Nietzsche, y MerleauPonty, devuelve al cuerpo su valor filosófico. Pues bien, esta importancia concedida al cuerpo, es también importancia concedida a la pasión. Y ello porque, como se ha tratado de poner de manifiesto, la materia que es cuerpo se define precisamente por la finitud y, junto con ella, por la pasión.

En conclusión, el naturalismo que es propio de la ontología de Spinoza es de carácter dinámico y va acompañado de elementos materialistas. Y, como se tratará de mostrar a continuación, en virtud de estas dos características, establece las condiciones de posibilidad para pensar desde un punto de vista ontológico las pasiones. El naturalismo de Spinoza es dinámico porque, como hemos visto, la Naturaleza, o lo real, es fundamentalmente potencia, esto es, dynamis y vis. A nivel de la Natura naturans, esa potencia es absolutamente infinita. La Naturaleza naturante tiene una potencia absoluta de existir y de obrar, $\mathrm{y}$, por tanto, no padece en ningún sentido. Dios no puede padecer. Atribuir afectos y pasiones a Dios sólo es fruto de una ficción, de una ilusión antropomórfica. En cambio, la Natura naturata, que también es potencia, es, al menos en parte, potencia finita. Y para los modos finitos, de potencia limitada, el padecimiento no es sólo posible, sino inevitable.

En los elementos materialistas del naturalismo spinoziano se encuentra una argumentación similar. La Extensión, como materia infinita, es un atributo de Dios. Sólo desde el punto de vista de la Natura naturata la materia es finita. Y entonces aparece el cuerpo propiamente dicho, y, con él, las pasiones y los afectos. Éstos, tal

${ }^{89}$ En cuanto al vínculo entre cuerpo, finitud y pasión, es especialmente significativo el libro V de la Ética y su proposición 34 antes citada: "El alma no está sujeta a los afectos comprendidos dentro de las pasiones sino mientras dura el cuerpo.” E, V, 34 (Geb. II, 301 ) (417).

90 Cf. E, II, 13, schol. (Geb. II, 98) (128-129); E, III, 2, schol. (Geb. II, 142) (197). 
y como ya se ha señalado, son, aunque no sólo, afecciones corporales. Y el vínculo entre el cuerpo y las pasiones es tal que una vez muere aquél, desaparecen éstas. En definitiva, el naturalismo ontológico spinoziano cuenta con dos características, el dinamismo y el cierto materialismo, que lo hacen especialmente propicio para albergar en su seno una reflexión ontológica sobre la pasión. Y así, el naturalismo spinoziano va acompañado de un último adjetivo que tiene que ver con lo afectivo y con lo pasional.

\section{Conclusión: ¿es la ontología naturalista de Spinoza una ontología de la pasión?}

La pasión, ¿es parte de lo real?, ¿es objeto de estudio de la ontología y, por tanto, hay que añadir su consideración a las características antes señaladas? $\mathrm{O}$, al menos, ¿posibilitan esas características el desarrollo de una ontología de la pasión?

Si empezamos por esto último, la respuesta es afirmativa. Una ontología naturalista que, al modo de la de Spinoza, estima que el dinamismo y la expresión de la potencia son dos rasgos básicos de lo real, no excluye, en principio, la pasión, elemento móvil donde los haya, de su reflexión. Además, la pasión tiene una estructura temporal finita ${ }^{91} \mathrm{y}$, por tanto, un estudio que quiera albergarla en su seno tiene que contar con la finitud como una categoría no necesariamente única, pero sí básica. Así hemos visto que lo hace la ontología spinoziana.

Por otra parte, la importancia que concede a la afección, y, por tanto, a la relación y a la corporalidad, hace de la filosofía de Spinoza una reflexión especialmente propicia para la consideración de la pasión como modo de ser. En este sentido, uno de los mayores prejuicios contra los que tiene que luchar una ontología de la pasión es el prejuicio del "espiritualismo" o "intelectualismo", es decir, la idea de que el cuerpo es un obstáculo para la filosofía y que ha de eliminarse, consecuentemente, de su reflexión. Y es que hay que reconocer que tenemos pasiones porque tenemos cuerpo; porque somos, entre otras cosas, cuerpo. De este modo, un requisito básico, quizá el principal, para un estudio ontológico de la pasión reside en suscribir una visión del mundo en cierto sentido materialista, esto es, estriba en reconocer que el cuerpo es un medio fundamental de trato con el mundo. $92 \mathrm{Y}$ así lo hace la filosofía de Spinoza.

\footnotetext{
91 Para una discusión desarrollada de la relación entre pasión y tiempo puede verse Nussbaum, M.: La terapia del deseo. Teoría y práctica en la ética helenística, Barcelona, Paidós, 2000, capítulo 6, pp. 247-301. [Trad. M. Candel] En este sentido, la autora afirma que "la amistad, el amor, la justicia y las diversas formas de acción moralmente virtuosa adquieren su sentido y valor dentro de la estructura del tiempo humano, como relaciones y actividades que se extienden sobre un tiempo finito." (Loc. cit., p. 287).

92 Cf. Gurméndez, C.: op. cit..
} 
Por último, la ontología de éste es una ontología de la razón, y esto, a primera vista, puede llevar al error de eliminar la pasión de su objeto de estudio. Sin embargo, tal y como arguye en repetidas ocasiones Spinoza, razón y pasión no son términos opuestos. ${ }^{93}$ De hecho, una de las labores que emprende en la Ética consiste en realizar una genealogía de las pasiones que pone de manifiesto cuáles se avienen naturalmente con la razón y cuáles no.

De este modo, puede concluirse que la ontología naturalista, de carácter dinámico y, hasta cierto punto materialista, que nos presenta Spinoza en el libro I de su Ética sienta las bases para el desarrollo de una reflexión ontológica sobre la pasión. No obstante, hay que matizar el sentido que esta ontología de la pasión puede tener en el sistema de Spinoza. Los hombres, afirma el filósofo, han atribuido erróneamente cuerpo y pasión a Dios. Pero Dios no padece. Ahora bien, Dios es Sustancia, Naturaleza, Ser, y si no puede padecer, ¿es que la pasión no pertenece de ninguna manera a éste? La respuesta es negativa. Y ello porque hay una esfera de lo real, o de la Naturaleza, en la que el padecimiento no sólo puede darse, sino que tiene lugar necesariamente. Ese ámbito es el ámbito de la Natura naturata, y, en concreto, de los modos finitos, y, así, del hombre. El hombre, afirma claramente Spinoza, está sujeto siempre, necesariamente, a las pasiones. ${ }^{94}$ Por tanto, no es exacto afirmar que lo real no tenga nada que ver con ellas. La ontología naturalista de Spinoza es, pues, una ontología de la pasión. Pero esta ontología es siempre regional, porque la pasión es un elemento ineliminable de esa parte del ser que es el hombre, y nunca general o absoluta, porque es imposible que Dios padezca. La pasión no es, pues, el Ser, pero sí es un modo suyo, un modo finito, humano, de ser. ${ }^{95}$

\footnotetext{
93 Véase, en este sentido, el magnífico prefacio del libro III de la Ética. Allí Spinoza señala que nadie hasta ahora ha podido determinar la naturaleza y la fuerza de los afectos, porque todos los que han reflexionado sobre ellos han considerado, erróneamente, que los afectos repugnan a la razón y que son antinaturales. Cf. E, III, Praef. (Geb. II, 137-138) (191-192).

94 "Hinc sequitur, hominem necessario passionibus esse semper obnoxium, communemque Naturæ ordinem sequi, et eidem parere, seseque eidem, quantum rerum natura exigit, accommodare." $\mathrm{E}, \mathrm{IV}, 4$, corol. (Geb. II, 213) (294).

95 Con ello lo que se pretende poner de manifiesto es que la pasión singulariza al hombre frente a Dios, esto es, singulariza y define ontológicamente a los modos finitos y no a la Sustancia infinita. En ese sentido, la pasión define al hombre, pero no de manera exclusiva. Hay otros modos finitos que no son humanos y que, sin embargo, también están necesariamente sometidos a las pasiones. La pasión que definirá al hombre será el deseo, es decir, una pasión que puede transformarse en un afecto activo racional, en la medida en que el deseo puede ir acompañado de conciencia. Cf. E, III, affectuum definitiones I (Geb. II, 190) (262).
} 


\section{Referencias bibliográficas}

ÁvilA, R.: "Finalidad, deseo y virtud: Spinoza y Nietzsche", Anales del Seminario de Metafisica, 20, 1985.

Currás, A.: "La doble articulación del discurso en la Ethica de Spinoza: tarea crítica y proyecto liberador", Anales del Seminario de Metafísica, 10, 1975.

De la CÁmara, M. L.: "Samuel Clarke contra Spinoza: la imagen de un adversario", Cuadernos del seminario Spinoza, 11, 2000.

Deleuze, G.: Spinoza et le problème de l'expression, Paris, Editions de Minuit, 1969. [Trad. H. Vogel, Spinoza y el problema de la expresión, Barcelona, Muchnik, 1975].

Deleuze, G.: Spinoza. Philosophie pratique, Paris, PUF, 1970. [Trad. A. Escohotado, Spinoza: filosofia práctica, Barcelona, Tusquets, 2001, 1ª ed. en Tusquets Fábula]

Deleuze, G.: Lógica del sentido, Barcelona, Seix Barral, 1971. [Trad. A. Abad]

Espinosa Rubio, L.: Spinoza: Naturaleza y Ecosistema, Salamanca, Publicaciones Universidad Pontificia de Salamanca, 1995.

Fernández, E.: Potencia y razón en B. Spinoza, Madrid, Editorial de la Universidad Complutense de Madrid, 1987.

FernÁndez, E. \& De la CÁmara, M. L. (eds.): El gobierno de los afectos en Baruj Spinoza, Madrid, Trotta, 2007.

Ferrater Mora, J.: Diccionario de filosofia, Barcelona, Ariel, 1994. (1 $1^{\mathrm{a} e d}$. revisada y actualizada en Ariel Referencia).

García Leal, J.: "El naturalismo ético en Spinoza", Ágora: papeles de filosofia, 4, 1984. "Física y ontología en Spinoza", Revista de Filosofía, 8, 1985.

Gueroult, M.: Spinoza. Dieu (Ethique I), vol. I, Paris, Aubier, 1968.

Giancotti, E.: Studi su Hobbes e Spinoza, Napoli, Bibliopolis, 1995.

GurmÉnDeZ, C.: Ontología de la pasión, México, Fondo de Cultura Económica, 1996.

JAQUeT, Ch.: Les expressions de la puissance d'agir chez Spinoza, Paris, Publications de la Sorbonne, 2005.

Matheron, A.: Individu et communauté chez Spinoza, Paris, Les Editions Minuit, 1969.

Misrahi, R.: Spinoza, Madrid, E.D.A.F., 1975. [Trad. F. L. Castre]

Negri, A. : L'anomalia selvaggia. Saggio su potere e potenza in Baruch Spinoza. Milán, Feltrinelli, 1981.

Nussbaum, M.: La terapia del deseo. Teoría y práctica en la ética helenística, Barcelona, Paidós, 2000. [Trad. M. Candel]

SpinozA, B.: Spinoza. Opera, Heidelberg, Carl Winters Universitätsverlag, 1972. [Edición de C. Gebhardt] 
SpinozA, B.: Ética demostrada según el orden geométrico, Madrid, Alianza Editorial, 1987. (5ª reimp. 2006) [Trad. Vidal Peña]

Peña GarCía, V.: El materialismo de Spinoza, Madrid, Revista de Occidente, 1974.

Yovel, Y.: Spinoza: el marrano de la razón, Madrid, Anaya \& Mario Muchnik, 1995. [Trad. M. Cohen]

Inmaculada Hoyos Sánchez

Universidad de Granada

Dpto. de Filosofía II.

ihoyos@ugr.es 